\title{
A Review on 5G Sub-6 GHz Base Station Antenna Design Challenges
}

\author{
Madiha Farasat ${ }^{1}$, Dushmantha N. Thalakotuna ${ }^{1, *}$, Zhonghao $\mathrm{Hu}^{2}$ and Yang Yang ${ }^{1}$ \\ 1 School of Electrical and Data Engineering, University of Technology, Sydney 2007, Australia; \\ Madiha.Farasat@student.uts.edu.au (M.F.); yang.yang-1@uts.edu.au (Y.Y.) \\ 2 Wireless Business Unit, Rosenberg Technology Australia, Northmead 2152, Australia; \\ nathan.hu@rosenbergerap.com \\ * Correspondence: dushmantha.thalakotuna@uts.edu.au
}

Citation: Farasat, M.; Thalakotuna, D.N.; Hu, Z.; Yang, Y. A Review on 5G Sub-6 GHz Base Station Antenna Design Challenges. Electronics 2021, 10, 2000. https://doi.org/10.3390/ electronics10162000

Academic Editor: Massimo Donelli

Received: 19 July 2021

Accepted: 12 August 2021

Published: 19 August 2021

Publisher's Note: MDPI stays neutral with regard to jurisdictional claims in published maps and institutional affiliations.

Copyright: (c) 2021 by the authors. Licensee MDPI, Basel, Switzerland. This article is an open access article distributed under the terms and conditions of the Creative Commons Attribution (CC BY) license (https:// creativecommons.org/licenses/by/ $4.0 /)$.

\begin{abstract}
Modern wireless networks such as 5G require multiband MIMO-supported Base Station Antennas. As a result, antennas have multiple ports to support a range of frequency bands leading to multiple arrays within one compact antenna enclosure. The close proximity of the arrays results in significant scattering degrading pattern performance of each band while coupling between arrays leads to degradation in return loss and port-to-port isolations. Different design techniques are adopted in the literature to overcome such challenges. This paper provides a classification of challenges in BSA design and a cohesive list of design techniques adopted in the literature to overcome such challenges.
\end{abstract}

Keywords: base station antenna challenges; multiband antennas; multibeam antennas; antenna arrays

\section{Introduction}

Base station Antenna (BSA) is the edge element in the air interface towards the mobile terminal in all communication systems, from the first-generation (1G) AMTS (advanced mobile telephone systems) to the fifth-generation (5G) networks. A significant amount of research and development has been done on BSAs; however, it appears largely disseminated across the literature. Thus, this communication aims to collate, categorize, and discuss the latest development and challenges associated with the BSAs.

There are two basic types of BSAs used in cellular communication systems: omnidirectional and directional (sector) antennas. These variants are used in almost all wireless technologies, from 1G to 5G. Omni-directional antennas are preferred for low-capacity and extended coverage scenarios such as in rural areas. In contrast, directional antennas are used to serve a targeted coverage area while providing a higher capacity. This targeted coverage, commonly known as a sector, is determined during mobile coverage planning. The serving sector antenna specifications are derived considering sector parameters.

The scope of this communication is to provide a comprehensive summary of recent BSA antenna designs and challenges, with particular interest placed on lower microwave bands in sub- $6 \mathrm{GHz}$ range. Whilst there is a significant amount of published work on BSAs, a cohesive discussion of BSA evolution with mobile technologies is not available. Hence, the antenna community will benefit from a brief discussion on how BSA technologies have evolved through mobile generations. This is discussed in Section 2 prior to discussing BSA challenges in detail in Section 3. Concluding remarks are drawn in Section 5.

\section{Evolution of BSA Technologies}

First-generation (1G) networks had omnidirectional cells, as the main focus was coverage, not the capacity. Hence, the BSAs, otherwise known as base transceiver station (BTS) antennas, were omnidirectional. As the number of users increased in the secondgeneration $(2 \mathrm{G})$ networks, operators started to consider ways to increase the capacity. One 
of the techniques used for capacity improvement is sectorization. A common sectorization technique used in $2 \mathrm{G}$ is to divide the previous omnidirectional cell into three sectors of $120^{\circ}$ each. As a result, three antennas, each having a $10 \mathrm{~dB}$ beamwidth of $120^{\circ}$, were used in the BTS.

Another technique used in $2 \mathrm{G}$ networks to enhance capacity is the use of polarization diversity. The aim was to provide two orthogonal polarizations in the antenna array. The horizontal $(\mathrm{H})$ and vertical (V) polarization were initially used, but $\pm 45^{\circ}$, otherwise known as slant polarization, has been widely adopted in many BTS antennas since $2 \mathrm{G}$. Figure 1a,b shows vertical and slant polarized dipole array configurations used in BSAs in $2 \mathrm{G}$ and following generations. The number of users increased rapidly, moving from $2 \mathrm{G}$ to $3 \mathrm{G}$ due to the introduction of mobile data services in 3G. As a result, operators had to explore further techniques to increase capacity. One solution was to further subdivide the sector into narrower sectors. This was done using narrow beam antennas with half-power beamwidth (HPBW) such as $65^{\circ}$ or even $33^{\circ}$. One of the disadvantages was increased antenna loading on the tower.

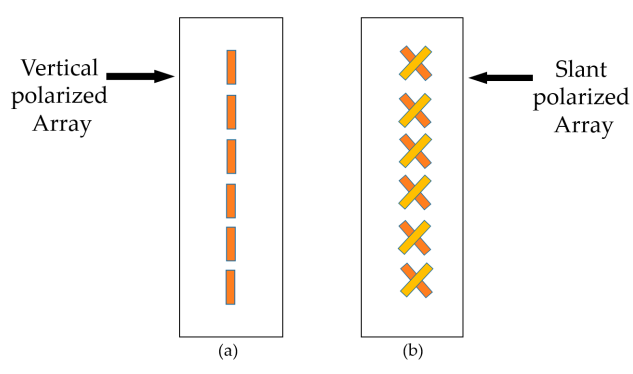

Figure 1. (a) Vertical polarized dipole array. (b) Slant polarized dipole array.

A solution to antenna loading was achieved by introducing multibeam panel antennas. Such antennas are similar in appearance to conventional sector antennas but have multiple narrow beams. As a result, increased capacity is achieved without the need for additional antennas, as shown in Figure 2. The twin beams or multibeams are achieved by introducing hybrid couplers into the feed network. These multibeam antennas have been a prevalent choice among operators for mobile networks since then.

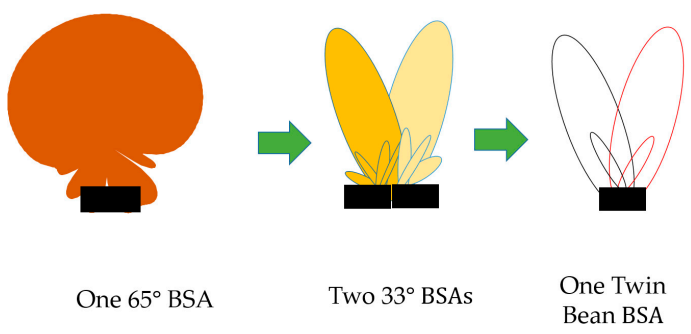

Figure 2. Patterns of a single-beam BSA, two narrow-beam BSAs, and a twin-beam BSA.

An increased number of cells/sectors requires comprehensive network planning to reduce cell edge interference and the need for operators to adjust the cell/sector coverage. This is achieved in a BSA antenna by providing beam tilting in the elevation plane. Most of the BSA antennas from 3G networks and later were equipped with a Remote Electrical Tilt (RET) feature, allowing the operator to remotely configure the elevation beam tilt in a $0-10^{\circ}$ range to optimize the network. The elevation beam tilt in the antenna is achieved using a phase shifter that provides a phase gradient to the elements in the antenna array. Therefore, most of the BSA antennas from 3G networks and beyond had the capability of beam tilting in the elevation plane. However, the elevation beam steering feature achieved using such phase shifters is only suitable for network optimization, not for beamforming in the elevation plane. With 2G and 3G technologies, an additional spectrum was introduced beyond previously used $800 \mathrm{MHz}$ and $900 \mathrm{MHz}$ bands. Primarily occupied 
higher frequency bands worldwide were in 1710-2100 MHz bands. With 4G LTE, additional spectra up to $2.6 \mathrm{GHz}$ were used worldwide. In $5 \mathrm{G}$, sub- $6 \mathrm{GHz}$ bands have an additional spectrum in $700 \mathrm{MHz}$ bands and 3.4-3.6 GHz bands. Therefore, with every generation, the existing spectrum is reused, while additional bands are introduced.

The radiating antenna elements used in BSAs, however, have limited bandwidth. Hence, a single element cannot operate in multiple bands. The most common approach in BSAs is to have two to three distinct radiating elements to cover these bands, i.e., one radiating element to cover lower bands 650-960 MHz [1] and another for 1695-2760 MHz [1-3] and a third element type to operate in 3.4-3.6 GHz [4]. As a result, each of these bands is provided by a separate antenna array. Although early $2 \mathrm{G}$ networks used separate antennas for each band, later generations used antennas with multiple bands in one housing. This technology is called multiband antennas. A multiband antenna has multiple arrays, each serving a different band within one enclosure. In the initial generations of multiband antennas, the arrays were physically separated as shown in Figure 3a. These multiband antennas provided space and weight savings compared to two separate antennas.

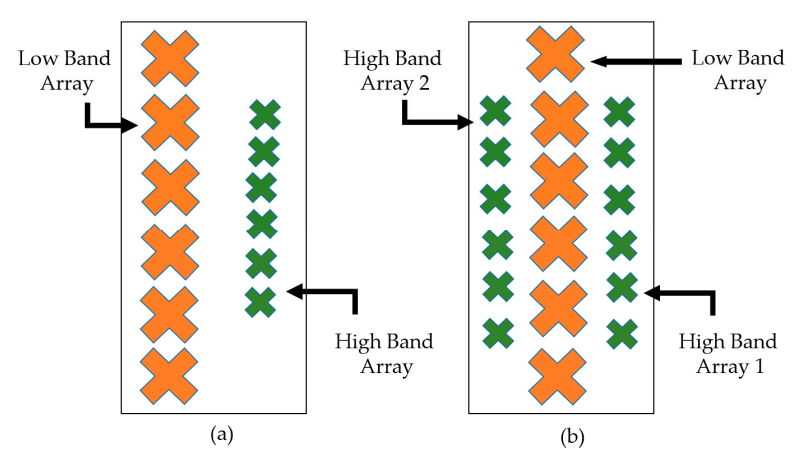

Figure 3. (a) Multiband antenna with physically separated arrays; (b) multiband antenna with interspersed arrays.

Later generations resulted in multiple interspersed arrays, as shown in Figure 3b, which further improved the space and weight savings. However, interspersed arrays present significant challenges during antenna designs, such as inter-band coupling and pattern distortions, discussed in detail in Section 3.2 of this paper.

The antenna arrays in higher frequency bands occupy less area since the vertical element spacing is much smaller in higher frequencies compared to lower frequency bands. Therefore, multiple higher-frequency band arrays can be accommodated with one low band array, as shown in Figure 4. The most common configurations were 1:2 or 1:4 array ratio between low band to high band. The antenna shown in Figure 4, has two ports for two polarizations used in low band array and two ports each for high band array, resulting in a total of 10 ports. This antenna architecture also allows multiple operators to share antenna arrays. Alternatively to such multiband arrays, antenna co-sharing was still practiced among operators using a diplexer to combine multiple bands into one BSA, even with single-band antennas. Some advanced BSAs in the $3 \mathrm{G}$ era comprised dual polar multiband and multibeam antennas.

Notable changes compared to previous mobile network generations in the air interface are first introduced with LTE-A. A significant increase in data rates is achieved in LTE-A due to MIMO capability. Up to eight layers of MIMO are first introduced in 3GPP Release 10. MIMO transmit data in parallel both in time and frequency in segregated streams. The BSAs are required to have spatially separated antenna arrays or polarization diversity to achieve the decorrelation in RF paths. The spatial separation has to be at least $0.7 \lambda$ or more [5]. Some of the multiband antennas used in 3G networks at the time already had 2-4 high band arrays already, and the operators could use them for MIMO operation without upgrading the BSA design. High band arrays are commonly used for MIMO operation, but some BSA designs can support up to 4 X MIMO for low band arrays as well [6]. 


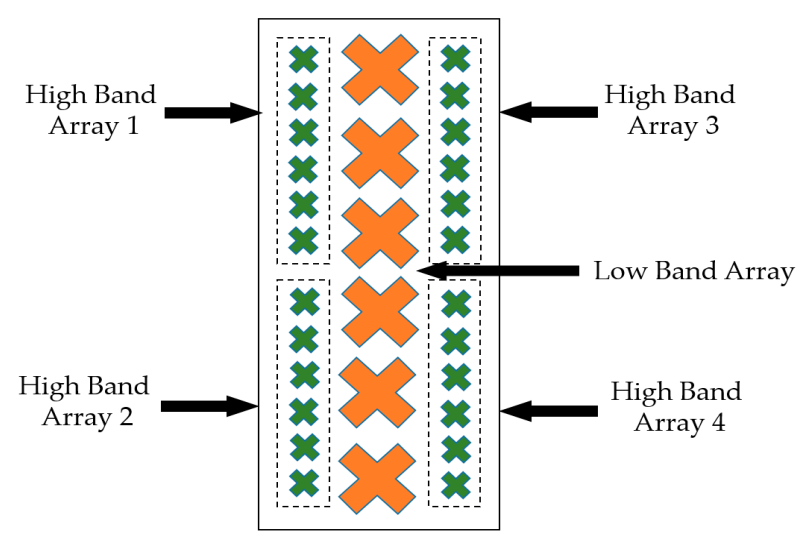

Figure 4. Low band to high band 1:4 antenna array configuration.

The 3GPP release 12 and 13 introduced active antenna systems (AAS) and massive MIMO (mMIMO) operation, which allowed real-time beamforming to provide increased capacity and reduced interference. These capabilities are adopted in 5G air interface and are commonly referred to as $5 \mathrm{G}$ antennas among the antenna community. The mMIMO with AASs are extensively used in mm-wave bands due to advancements in the Antenna in Package (AiP) and millimeter-wave integrated circuit (MMIC) technologies. The smaller wavelengths at mm-wave require only small antenna footprints, allowing them to be directly integrated with the transceivers. However, the peak power limitations, efficiencies at $\mathrm{mm}$-wave transceivers and propagation and penetration losses at mm-wave frequencies limit the use of mm-wave BSAs to indoor use and small cells. The mMIMO in sub- $6 \mathrm{GHz}$ is also used by the operators for outdoor coverage due to low propagation and penetration losses at these frequencies. The challenges at mm-wave antennas have significant differences to the sub-6 GHz BSAs. Within the scope of this discussion, we present the challenges associated with the BSAs in sub-6 GHz and below, as these BSAs are the most widely used antennas by the operators to date.

The mMIMO aims to control the Signal-to-Noise Ratio (SNR) to each user by forming beams to each user unlike single-user MIMO and Multi-User MIMO in LTE and LTE-A. This requires a two-dimensional antenna array with control on the amplitude and phase to steer the beam in azimuth and elevation. The conventional beamforming antenna arrays require the element spacing to be $0.5 \lambda$ to reduce the grating lobes. In contrast, the MIMO demands more spacing between the arrays to increase spatial diversity at least $0.7 \lambda$ or more. In practice, a compromise is made, and a $0.65 \lambda$ column spacing is used in most of the mMIMO antennas. The need to form the beam requires a phase and amplitude control at each radiating element, which can be done using either via analog beamforming architecture, digital beamforming architecture, or a hybrid beamforming architecture. The analog and digital beamforming architectures that are the most commonly used are shown in Figure 5. Analog beamforming has a significantly lower power consumption than the digital beamforming technique due to a lack of active components. However, in practice, analog beamforming cannot provide true mMIMO capability because the beams formed by analog beamforming are either multiple fixed beams or steer at a much slower rate compared to the digitally formed beams. In practice, analog beamforming is achieved by either a beamforming network such as Butler Matrix [7] or using a lens [8]. Digital beamforming is the preferred architecture in Sub-6 GHz mMIMO antennas as most of the beamformers can provide IF outputs up to $6 \mathrm{GHz}$. Hybrid beamforming architecture is mostly used in mm-wave $5 \mathrm{G}$ realizations in order to achieve power savings and reduce complexity in the designs. More details on the current sub-6 GHz adapted beamforming technologies and the challenges are discussed in Section 3.3. 


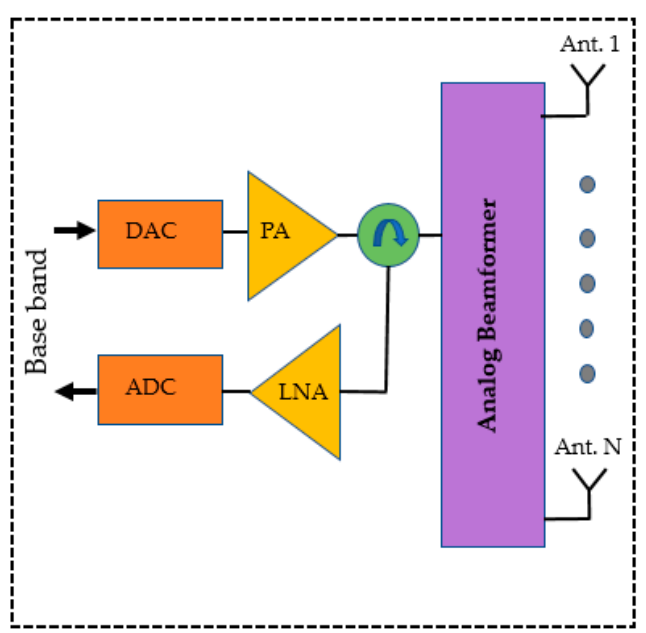

(a)

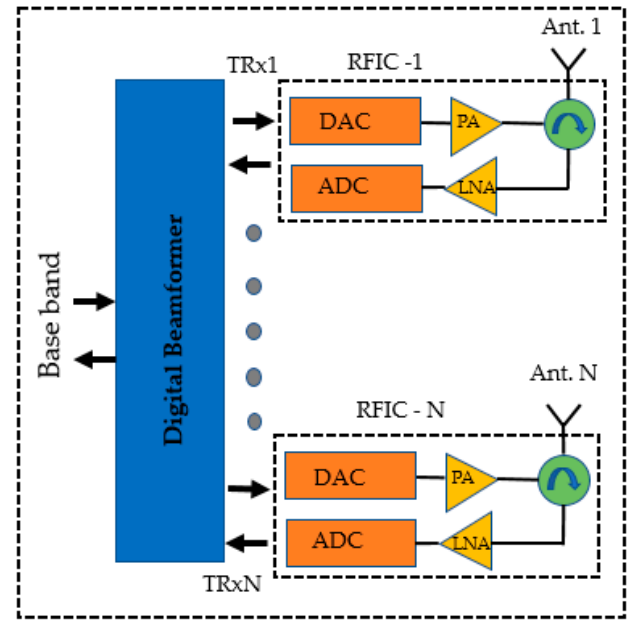

(b)

Figure 5. (a) Analog beamforming architecture; (b) digital beamforming architecture.

\section{Challenges in BSA Design}

The challenges associated with the BSAs are classified into three main categories, as shown in Figure 6. The "port measurements" include the design challenges in achieving wide impedance bandwidths and meeting the port-to-port isolation requirements. The challenges in radiation patterns are mostly due to the interspersed nature of the multiband arrays: the radiating elements of other bands causing scattering and undesirable effects on the radiation patterns. Therefore, the radiating elements of one band have to be made almost transparent for the other band and vice versa. The size constraints are another challenge faced by BSA designers. The real estate available on an antenna tower is very limited and costly; therefore, smaller compact antennas without any electrical performance degradation are always preferred.

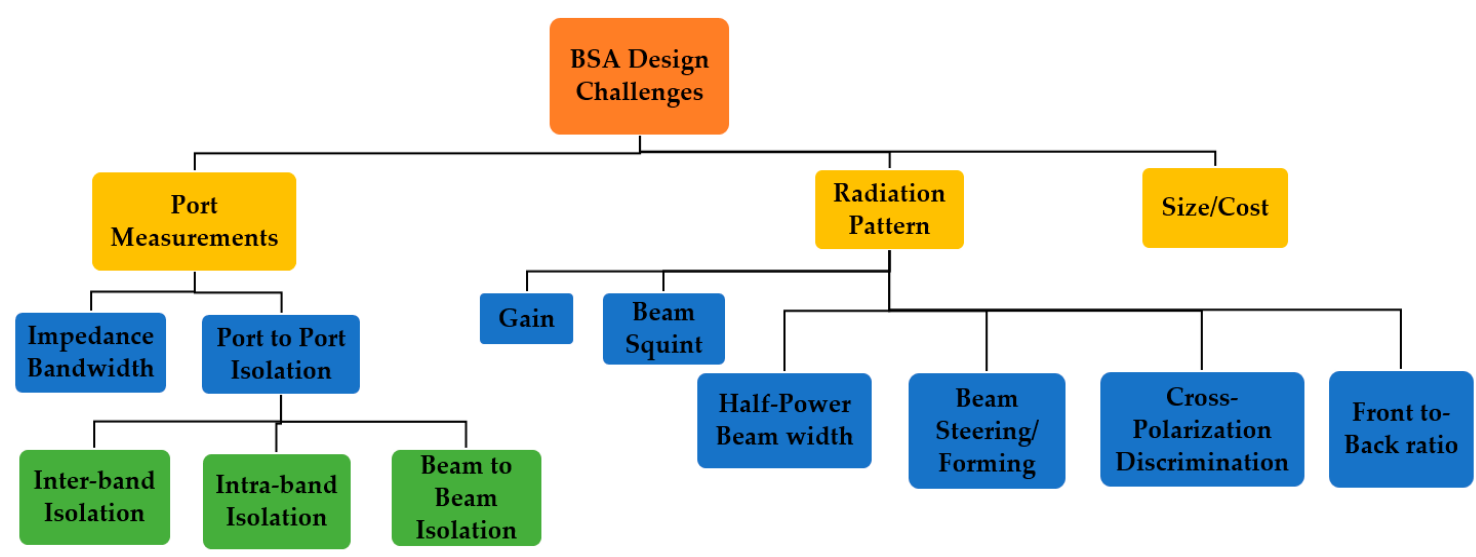

Figure 6. Classification of base station antenna challenges based on design.

Prior to proceeding with details in each challenge area, it is worth providing a general overview of the reported solutions in the literature for each of these challenges. Hence, a summary of available solutions/techniques reported in the literature for some of the key design challenges is provided in Table 1. These challenges highlighted in Figure 6 are discussed in detail in Sections 3.1-3.4. 
Table 1. A summary of available solutions for design challenges in Base Station Antenna design.

\begin{tabular}{|c|c|c|}
\hline Design Challenge & Solutions/Techniques & References \\
\hline \multirow{3}{*}{ Achieving wide impedance bandwidth } & Wideband balun design & [9-12] \\
\hline & Modification to radiator shape & [13-15] \\
\hline & Use of parasitic element/s to widen bandwidth & [16-20] \\
\hline \multirow{2}{*}{ Achieving high isolation levels } & Use of differential feed structure & {$[16,21,22]$} \\
\hline & Use of decoupling network & {$[15,23,24]$} \\
\hline \multirow{2}{*}{ Stable HPBW in bandwidth of operation } & Cavity shape reflector & [16] \\
\hline & Convex shaped reflector & [19] \\
\hline Achieving high front-to-back ratio & $\begin{array}{c}\text { Modifications to the radiator-Downward } \\
\text { sloping dipoles }\end{array}$ & [25] \\
\hline Minimizing Beam Squint & $\begin{array}{l}\text { Enforce symmetric current distribution on the } \\
\text { radiating element }\end{array}$ & [26-28] \\
\hline Achieving high Cross polarization discrimination & Modifications to the radiator shape & {$[29,30]$} \\
\hline Improving the gain & $\begin{array}{l}\text { Modifications to the radiator-addition of notch } \\
\text { metal wall }\end{array}$ & {$[30]$} \\
\hline \multirow{3}{*}{ Achieving beam steering } & Butler matrix & [7] \\
\hline & Luneburg lens & [8] \\
\hline & Digital beamforming-integrated RF transceiver & [31] \\
\hline Achieving compact size designs/cost & Multiband compact radiating element design & {$[2,4,32,33]$} \\
\hline
\end{tabular}

\subsection{Port Measurements: Impedance Bandwidth}

One of the key challenges for the modern base station antennas is the bandwidth. While the spectrum is harmonized for certain mobile telecommunication bands, different countries tend to use different portions of the spectrum based on the license given to operators. It is desirable to design base station antennas to cover the entire allocated spectrum despite operators not having access to full bandwidth as it allows one antenna design to be used globally instead of variants for different geographic markets. However, it is difficult to design a single base radiating element that operates in all the frequency bands listed in Table 2. Hence, it is often the practice to use multiple radiating elements to cover multiple bands.

Table 2. Widely adapted frequency bands for mobile communication systems.

\begin{tabular}{ccc}
\hline No. & Systems & Bands (MHz) \\
\hline 1 & FDD 1700 & $1690-1710$ \\
2 & DCS & $1710-1880$ \\
3 & PCS & $1850-1990$ \\
4 & UMTS & $1920-2170$ \\
5 & LTE & $2300-2400$ \\
6 & LTE+ & $2570-2700$ \\
7 & GSM850 & $880-915$ \\
8 & GSM900 & $925-960$ \\
9 & Sub-6 & $3300-3600$ \\
10 & mm-wave & $24,000-28,000$ (Non-contiguous)
\end{tabular}

Impedance bandwidth is an important measure in BSAs as it provides the frequency band in which a minimum return loss level is achieved. Typically this is about $14 \mathrm{~dB}$ for BSAs [34]. It can be challenging to achieve the return loss requirements over a wide band. This wideband matching needs to be achieved both for radiating elements as well as the feed network to meet the requirements. Generally, the techniques used to widen the impedance bandwidth can be categorized into three parts. (a) Use of a wideband Balun (b) modifications to radiator, and (c) use of parasitic elements. 


\subsubsection{Wideband Balun}

A generic and the most adopted Balun design is shown in Figure 7. The $50 \Omega$ transmission feed is transformed to a balanced feed through an impedance transformer as shown in Figure 7a. This is then fed to the dipole via a series LC resonator. This series LC resonator may be required depending on the impedance presented by the dipole. It is usually not required for a halfwave dipole but is used for longer dipoles. The implementation of the Balun on a microstrip feed or otherwise known as stalk is shown in Figure $7 \mathrm{~b}$. The $50 \Omega$ feed is connected at the bottom of the stalk, which is underneath the reflector once mounted on the antenna (Figure 7c). The first transmission line (TL) and Open line (OL) at the input side of the transformer is implemented on the front side of the stalk. The backside balanced Short Line (SL), which is also connected to the reflector ground, acts as the ground for TL and OL microstrip lines printed on the front. The balanced Open Line (OL) then has a provision to include two inductors. The dipoles are soldered to one side of the capacitor on the top. The area of the parallel printed metals is adjusted to provide the required capacitance. It should be noted that Figure 7, only shows the feed for one polarization only. Two of such stalks can be combined together to feed a dual polar design.

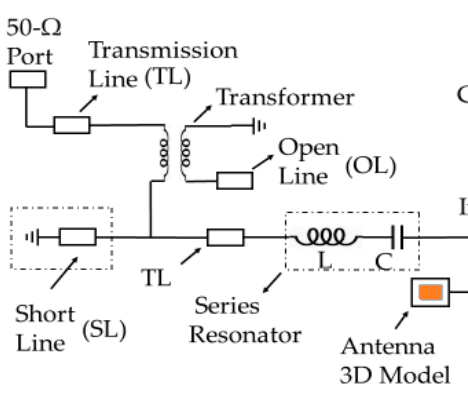

(a)

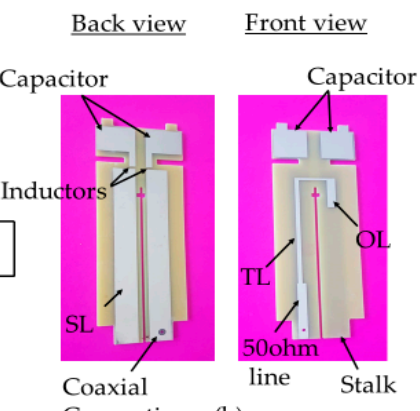

Connection (b)

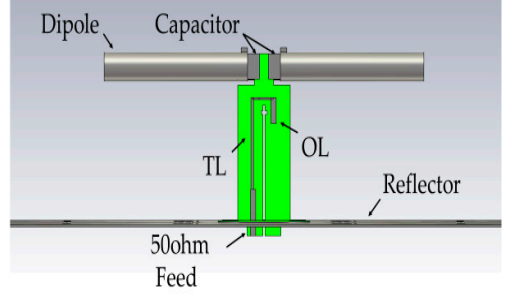

(c)

Figure 7. (a) Circuit representation of the matching circuit for the feed. (b) Microstrip implementation of the matching circuit (c) Side view of the radiating element.

The variations of this generic Balun are often used in many designs to achieve wider impedance bandwidths. Some of the reported works include L-probe feed with impedance bandwidth 54\% [9], Y shaped feeding line with impedance bandwidth of 45\% [10], T probe line [11] with impedance bandwidth of $71.17 \%$, and shorted stub with impedance bandwidth $27.6 \%$ in [12]. In [35], microstrip to slot line balun is used to improve impedance matching with return loss better than $14 \mathrm{~dB}$ over the operating band $1710-2170 \mathrm{MHz}$. Slot line impedance is controlled through slot and ground width. The feed point height adjustment is a common parameter used during the Balun design to achieve a broader bandwidth [36].

\subsubsection{Modifications to Radiator}

Some of the commonly used techniques include various shapes of dipole [37], multidipole [13], and loop-shaped dipoles [10,14]; however, some of these techniques result in larger aperture size and limit the design freedom. In [15], a 55\% wide impedance bandwidth is achieved from 1.65 to $2.9 \mathrm{GHz}$ by using a fan-shaped etching slot and chamfering quadrants along the diagonal dipole arms. The resulting prototype increased the radiation area and extended the current path to help improve the bandwidth. A bowtie antenna modeled by a Bezier spline was proposed to have a bandwidth of $68 \%$ from $1.427-2.9 \mathrm{GHz}$ [38]. The multi-dipole antenna proposed in [13] achieved wider impedance bandwidth of $60 \%$ from 1.55 to $2.87 \mathrm{GHz}$.

A multimode antenna with an embedded double loop configuration proposed in [14] has an impedance bandwidth of $51 \%$ from 1.68 to $2.83 \mathrm{GHz}$. In this design, a small loop inside an outer loop is added to generate a new resonant mode and hence widen the impedance bandwidth. In [39], a comparison of different patches with and without slots, 
including shorting strip, is performed to identify the structure that provides the widest impedance match. This comparison shows that the position of the coaxial feed cables, chamfer dimensions, and shape of the slotted patch contributed to $21.7 \%(0.82-1.02 \mathrm{GHz})$ and $49.5 \%(1.64-2.72 \mathrm{GHz})$ impedance bandwidth.

\subsubsection{Use of Parasitic Elements}

Another method is to use parasitic elements to improve the impedance bandwidth. An octagonal loop dipole in [10] achieved an impedance bandwidth of $45 \%$. These loop dipoles show wider impedance bandwidth compared to fundamental quarter wave dipoles. When one loop dipole is excited, the other behaves like a parasitic element to improve the bandwidth. The length of the parasitic loop element is optimized in [16] to achieve an impedance bandwidth of $52 \%$ from 1.7 to $2.9 \mathrm{GHz}$.

In [17], an antenna array with a bandwidth of $70 \%$ from $1.32-2.74 \mathrm{GHz}$ is designed. The antenna configuration is a U-shaped slot etched on each polarization leaf of the element. A parasitic element with four layers of circular metal disks is introduced to improve the impedance bandwidth. It is found that the number of layers of the parasitic elements directly improves the impedance matching. The operating principle follows the rule that the radiation resistance exhibited in a dipole is proportional to the square of the electrical length of the current path [18]. The addition of a parasitic element makes the reactance of impedance be tuned either capacitive or inductive to achieve the best match. In [19], a parasitic patch was placed above the folded dipole to enhance the bandwidth to $64.7 \%$ from 1.4-2.77 GHz. In [20], the antenna showed 63\% impedance bandwidth within the 1.68-3.23 GHz range due to the parasitic element. In [40], the resonator-loaded dipole antenna with a U-shaped strip feed widened the bandwidth by moving two resonating modes closer to each other. The length of the resonator and distance between resonator and dipole is optimized to achieve a $37.5 \%$ impedance bandwidth from 0.67 to $0.98 \mathrm{GHz}$. Although inserting parasitic elements is a unique approach to solve the matching issue, it can adversely impact the radiation pattern performance.

\subsection{Port Measurements: Port to Port Isolation}

The increased use of multiband, multibeam, and dual-polarized base station antennas for cost and space savings leads to challenges in achieving isolation requirements. The port-to-port isolation indicates how well any two RF signals on a multiport or MIMO antenna are decoupled from each other. In general, isolation can be categorized into three main types: intra-band isolation, inter-band isolation, and beam-to-beam isolation.

Intra-band isolation is the coupling between the polarizations of the same/multiple antenna arrays within the same frequency band. This is often referred to as cross-polar isolation when measured within the same array. Figure 8a shows a two-port BSA where each port represents two orthogonal polarizations of the same array, while Figure $8 \mathrm{~b}$ shows a four-port BSA with two antenna arrays of same band. Ports 1 and 2 feed orthogonal polarizations of array 1, while ports 3 and 4 feed the two polarizations of array 2 . The isolation between any of the ports 1 to 4 represents intra-band isolation. Generally, the intra-band isolations are required to be greater than $25 \mathrm{~dB}$ or $30 \mathrm{~dB}$ [34], depending on the frequency range of operation and operator requirements.

Inter-band isolation denotes the coupling between the arrays of different bands. In Figure 9, a dual-band antenna example is given, in which ports 1 and 2 represent feeds for Band 1, and ports 3 and 4 represent feeds for Band 2. The |S13|, |S14 |, |S23 |, and | S24 | represent the inter-band isolation between ports of high and low band elements. In multiband antennas, the isolation is measured in all frequency bands of operations, and typically these levels need to be above $30 \mathrm{~dB}$ or higher. 


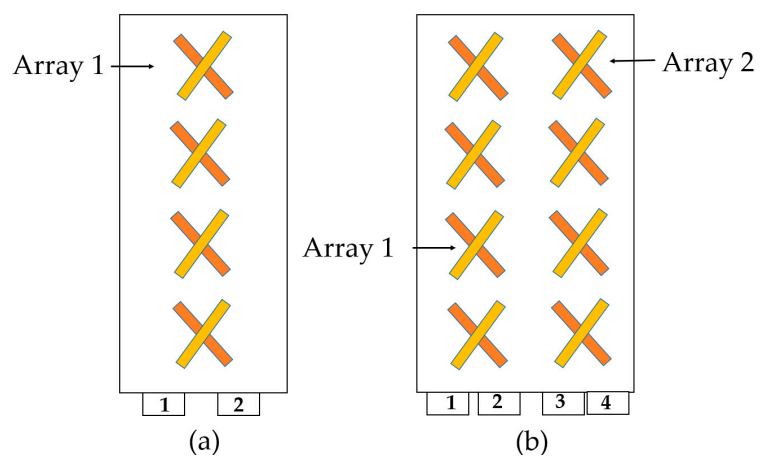

Figure 8. (a) Two-port single band antenna. (b) Four-port single band antenna.

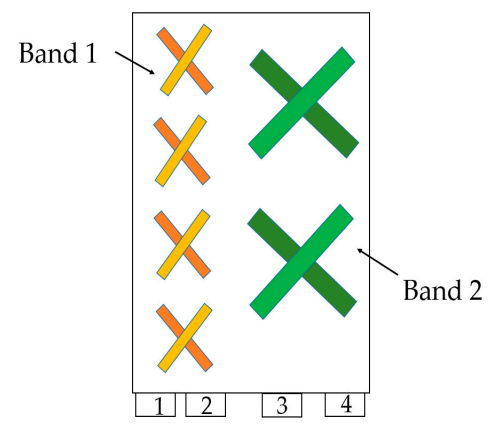

Figure 9. A dual-band antenna.

The higher the number of arrays in the antenna, the higher the port-to-port isolation combinations. Table 3 shows all possible port-to-port isolation combinations for a singlebeam multiband antenna shown in Figure 4. The row entries in Table 3 are depicted as transmitting arrays, while the column entries are depicted as receiving arrays to make it simpler to distinguish the coupled band of interest. For example, $\mathrm{HB}_{\mathrm{tx}}-\mathrm{LB}_{\mathrm{rx}}$ indicate the $\mathrm{HB}$ array 1 coupling to $\mathrm{LB}$ array at High Band frequencies, while $\mathrm{LB}_{\mathrm{tx}}-\mathrm{HB} 1_{\mathrm{rx}}$ indicate the LB array to HB array 1 coupling at Low Band frequencies. All diagonal entries in the table represent cross-polar isolations within the same band. All non-diagonal entries represent coupling between different arrays of the same band or a different band. It should also be noted that all non-diagonal entries can be further divided into four entries since the arrays are dual polarized. For example, $\mathrm{LB}_{\mathrm{tx}}-\mathrm{HB} 1_{\mathrm{rx}}$ comprises $\mathrm{LB}_{+45}-\mathrm{HB}_{+45}, \mathrm{LB}_{+45}-\mathrm{HB}_{-45}, \mathrm{LB}_{-45^{-}}$ $\mathrm{HB}_{+45}$, and $\mathrm{LB}_{-45}-\mathrm{HB}_{-45}$, where subscripts +45 and -45 represent two slant polarizations. Usually, the isolation between orthogonal polarizations is always better compared to the same polarization.

Beam-to-beam isolation is a special case applied for multibeam antennas representing the coupling between each beam in the array. Typically, the beam-to-beam isolation needs to be $20 \mathrm{~dB}$ or higher.

The techniques used to improve isolation performance include differential feeding and decoupling network/structures. Differential feed structure, in theory, can provide infinite isolation in a dual-polarized symmetrical feed since an excitation of one port does not induce common mode or different voltage currents in the other port. In practice, intra-band isolation greater than $36 \mathrm{~dB}$ [21] and $26 \mathrm{~dB}$ [16] were achieved through a differential fed scheme. In [22], folded feeding lines based on differential feeding techniques are used to achieve intra-band isolation larger than $43 \mathrm{~dB}$.

Decoupling networks are also another technique used to improve port-to-port isolations. Coupled resonator-based decoupling network is deployed in [41] to improve inter-band isolation from 8 to $10 \mathrm{~dB}$. The currents induced by the coupled resonator helps to cancel the strong coupling between antennas operated in two frequency bands. Decoupling and matching network techniques implemented in [42] achieve inter-band isolation level over $10 \mathrm{~dB}$ in the $1.71 \mathrm{GHz} \mathrm{t}-1.76 \mathrm{GHz}$ and $2.27-2.32 \mathrm{GHz}$ bands. 
Table 3. Port-to-port isolation combinations for the multiband antenna depicted in Figure 4.

\begin{tabular}{|c|c|c|c|c|c|}
\hline Transmitter/Receiver & LB Array $_{r x}$ & HB Array $1_{\mathrm{rx}}$ & HB Array 2 rx & HB Array $3_{r x}$ & HB Array $4_{r x}$ \\
\hline LB Arraytx & $\begin{array}{l}\text { Cross polar } \\
\text { isolation }(\mathrm{LB})\end{array}$ & $\mathrm{LB}_{\mathrm{tx}}-\mathrm{HB} 1_{\mathrm{rx}}$ & $\mathrm{LB}_{\mathrm{tx}}-\mathrm{HB} 2_{\mathrm{rx}}$ & $\mathrm{LB}_{\mathrm{tx}}-\mathrm{HB} 3_{\mathrm{rx}}$ & $\mathrm{LB}_{\mathrm{tx}}-\mathrm{HB} 4_{\mathrm{rx}}$ \\
\hline HB Array $\mathbf{1}_{\mathrm{tx}}$ & $\mathrm{HB}_{\mathrm{tx}}-\mathrm{LB}_{\mathrm{rx}}$ & $\begin{array}{l}\text { Cross polar } \\
\text { Isolation }(\mathrm{HB})\end{array}$ & $\mathrm{HB} 1_{\mathrm{tx}}-\mathrm{HB} 2_{\mathrm{rx}}$ & $\mathrm{HB} 1_{\mathrm{tx}}-\mathrm{HB} 3_{\mathrm{rx}}$ & $\mathrm{HB} 1_{\mathrm{tx}}-\mathrm{HB} 4_{\mathrm{rx}}$ \\
\hline HB Array $2_{t x}$ & $\mathrm{HB} 2_{\mathrm{tx}}-\mathrm{LB}_{\mathrm{rx}}$ & $\mathrm{HB} 2_{\mathrm{tx}}-\mathrm{HB} 1_{\mathrm{rx}}$ & $\begin{array}{l}\text { Cross polar } \\
\text { isolation }(\mathrm{HB})\end{array}$ & $\mathrm{HB} 2_{\mathrm{tx}-} \mathrm{HB} 3_{\mathrm{rx}}$ & $\mathrm{HB} 2_{\mathrm{tx}}-\mathrm{HB} 4_{\mathrm{rx}}$ \\
\hline HB Array $3_{t x}$ & $\mathrm{HB}_{\mathrm{tx}}-\mathrm{LB}_{\mathrm{rx}}$ & $\mathrm{HB} 3_{\mathrm{tx}}-\mathrm{HB} 1_{\mathrm{rx}}$ & $\mathrm{HB}_{\mathrm{tx}}-\mathrm{HB} 2_{\mathrm{rx}}$ & $\begin{array}{l}\text { Cross polar } \\
\text { isolation }(\mathrm{HB})\end{array}$ & $\mathrm{HB}_{\mathrm{tx}}-\mathrm{HB} 4_{\mathrm{rx}}$ \\
\hline HB Array $4_{t x}$ & $\mathrm{HB} 4_{\mathrm{tx}}-\mathrm{LB}_{\mathrm{rx}}$ & $\mathrm{HB} 4_{\mathrm{tx}}-\mathrm{HB} 1_{\mathrm{rx}}$ & $\mathrm{HB} 4_{\mathrm{tx}}-\mathrm{HB} 2_{\mathrm{rx}}$ & $\mathrm{HB} 4_{\mathrm{tx}}-\mathrm{HB} 3_{\mathrm{rx}}$ & $\begin{array}{l}\text { Cross polar } \\
\text { isolation }(\mathrm{HB})\end{array}$ \\
\hline
\end{tabular}

As discussed in Section 3.4, the compactness of BSA design embedded scheme can cause low isolation. Different techniques were tried to improve the isolation in such schemes. In [1], a ring-shaped baffle is placed between the lower band and high band elements to decouple the two bands and achieve port-to-port isolation of $23 \mathrm{~dB}$ in the low band $(0.77$ to $0.98 \mathrm{GHz})$ and $17.5 \mathrm{~dB}$ in the high band $(1.65$ to $2.9 \mathrm{GHz})$. In [43], a similar configuration, in which a high band element nested inside a lower band, is used. Four arc-shaped baffle plates are used in this work, which results in port isolation greater than $27.3 \mathrm{~dB}$ for the lower band 704-960 MHz and $28.3 \mathrm{~dB}$ for the high band $1710-2690 \mathrm{MHz}$. The $\pm 45^{\circ}$ dual-polarized antenna with the dielectric cavity achieves crosspolar isolation of $40 \mathrm{~dB}$ in [44] using carefully positioned symmetrical two shorting pins in the coax feedline. An orthogonal coupled sectorial loop-antennas with a cavity is used to achieve $>30 \mathrm{~dB}$ intra-band isolation over a $1710-2170 \mathrm{MHz}$ band in [35]. Decoupling networks such as bandgap structure [45], band stop decoupling unit [23], and filtering antenna elements [24] are also some commonly used techniques.

A filtering technique with different configurations is employed to get better isolation. C-shaped filtering stubs as shown in Figure 10a are introduced in [15] for achieving portto-port isolation $>25$. The purpose of the filtering stub is to control the current flow across the feeding line of the relevant port to act as a band stop for the specific band to achieve high isolation. Filtering response through parasitic elements as shown in Figure 10b is realized in [20], resulting in improved isolation of greater than $32 \mathrm{~dB}$. The basic filtering structures include metasurface structure [46], slot [47], shorting vias [48], and parasitic elements [49], and defected ground structure [50] integrated with the radiator to achieve the filtering response for base station application. Although an extra filtering structure increases insertion loss, the filtering antenna as array elements without extra decoupling structure has been proposed in [24]. The radiating element realized the filtering response by adding the shorting pins and E-slot to achieve inter-band isolation of $35 \mathrm{~dB}$. Balun design is modified to provide required filtering removing the need to have additional filters in [51]. Intra-band isolation $>31 \mathrm{~dB}$ is achieved in [52] by carefully designing the dipoleto mutual coupling to complement the cross-polar isolation.

A configuration named lower-band-ground-upper-band (L-G-U), where the highband antennas are located above the lower-band antenna separated by a low pass surface, is presented in [53]. It demonstrates inter-band isolation better than $30 \mathrm{~dB}$ in both working bands. In [54], a frequency selective surface is introduced between the high band and low band elements in the $\mathrm{L}-\mathrm{G}-\mathrm{U}$ configuration to achieve inter-band isolation $>25 \mathrm{~dB}$. The frequency-selective surface is optimized to serve as top capacitive loading for low-band 0.69-0.96 GHz and act as a reflector for high-band 3.5-4.9 GHz. In [55], beam-to-beam isolation $>32 \mathrm{~dB}$ was achieved through Luneburg lens. This Luneburg lens antenna operates from $1710-2690 \mathrm{MHz}$, made up of a special periodic structure to become suitable for base station application. In the literature, a Luneburg lens with different materials was 
designed such as in [56], which is configured with a metamaterial layer to make it compact at lower frequencies $(0.8-6 \mathrm{GHz})$.

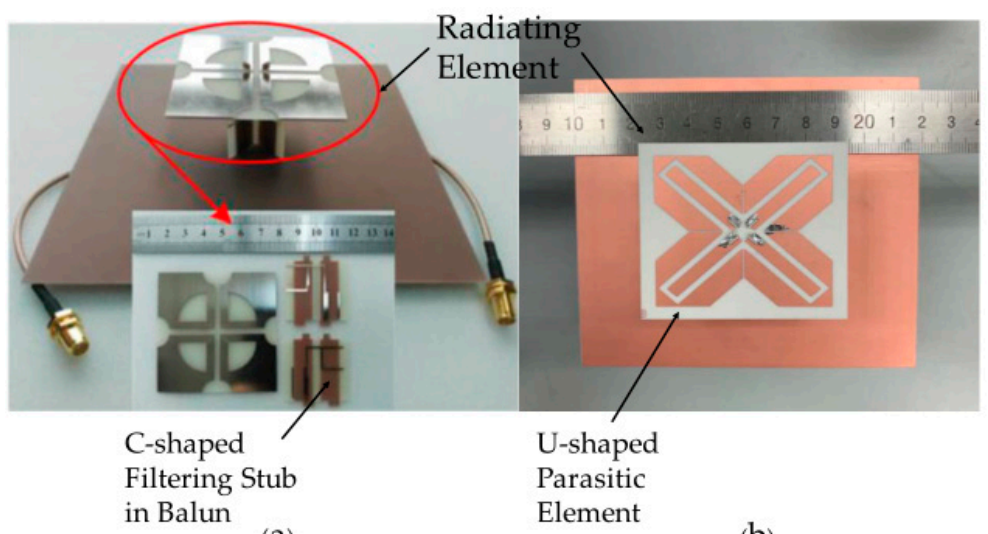

(a)

(b)

Figure 10. (a) Proposed antenna configuration [15]. (b) Parasitic element configuration in proposed antenna [20].

\subsection{Radiation Patterns}

The far-field radiation patterns are a very important, if not the most important, factor for an operator. Some critical parameters in patterns include $3 \mathrm{~dB}$ beamwidth, $10 \mathrm{~dB}$ beamwidth, beam squint, front-to-back (F/B) ratio, sidelobe levels, and cross-polarization discrimination (XPD). Some of these parameters are marked in Figure 11. The specifications provided by the operators to antenna designers can slightly change but mostly follow the industry-standard requirements listed in [34].

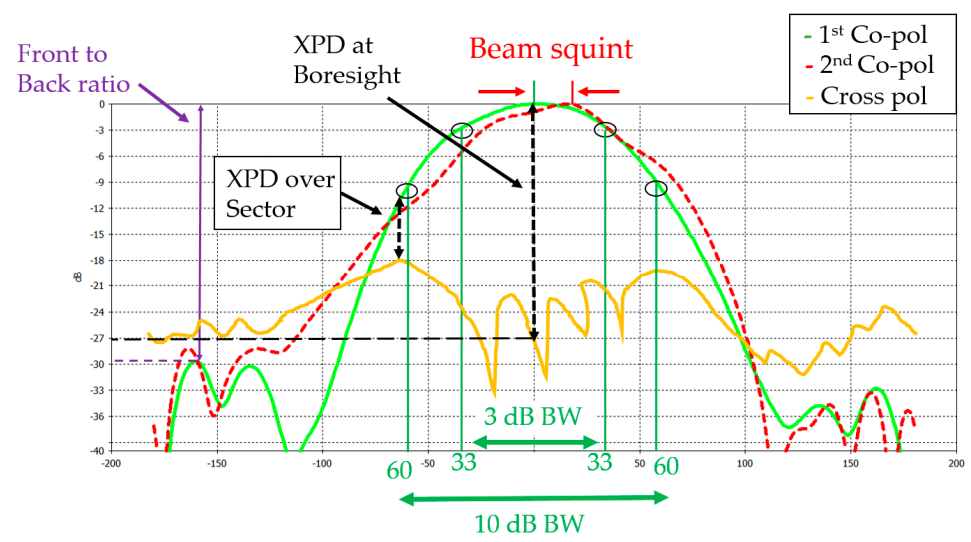

Figure 11. Illustration of some critical parameters for antenna radiation pattern.

The beamwidths $3 \mathrm{~dB}$ and $10 \mathrm{~dB}$ are important in network planning to mark sector footprints. Usually, single beam/sector antennas must have an HPBW requirement of $65^{\circ}$ for three sector cell sites and $45^{\circ}$ or $33^{\circ}$ for six sector sites. The $10 \mathrm{~dB}$ beamwidth refers to the angular beamwidth at $10 \mathrm{~dB}$ below the peak values. It is desirable to have a $10 \mathrm{~dB}$ beamwidth of $120^{\circ}$ in a three-sector site which implies that signal strength at the sector edge is $10 \mathrm{~dB}$ below the peak in boresight.

The radiation element most often needs modifications in its design to achieve the desired azimuth beamwidth. The important factors that affect the azimuth beamwidth are the length of the radiator and the distance between the radiator and reflector. These parameters are optimized to attain $3 \mathrm{~dB}$ beamwidth within the range of $65.7^{\circ} \pm 3.2^{\circ}$ [19]. The use of dipole-type radiators is common in radiating element design. The umbrellashaped dipoles are configured in [57] to achieve an HPBW (half-power beamwidth) of $63^{\circ} \pm 5^{\circ}$ in the H-plane. Another technique to modify the azimuth beamwidth is the use 
of cavity-shaped reflector over a planer reflector [58]. Further, rectangular cavity-shaped reflectors in [16] and convex-shaped reflectors in [19] are used to achieve $3 \mathrm{~dB}$ beamwidth around $65^{\circ} \pm 5^{\circ}$. The length and height of the reflector primarily affect the $3 \mathrm{~dB}$ beamwidth in the H-plane. This effect is realized in [10] to achieve a $3 \mathrm{~dB}$ beamwidth $68^{\circ} \pm 2^{\circ}$ at $\mathrm{H}$ plane and V-plane. It is found that increasing the length of the box-shaped reflector narrows the beamwidth in lower frequencies and widens the beamwidth in high frequencies in the band 1.7 to $2.7 \mathrm{GHz}$.

Another critical parameter in radiation patterns is the front-to-back $(\mathrm{F} / \mathrm{B})$ ratio. A higher $\mathrm{F} / \mathrm{B}$ ratio is desirable to minimize backward radiation that can contribute to cochannel interference. Typical values need to be $25 \mathrm{~dB}$ or more in most of the base station antenna designs. Having a large reflector helps improve the F/B ratio. However, most of the BSAs have size constraints in terms of antenna width. Different topologies have been adopted in the literature to achieve the desired $\mathrm{F} / \mathrm{B}$ ratio. Radiating elements proposed in [25] have downward-sloping dipoles, which improves the $\mathrm{F} / \mathrm{B}$ ratio. An $\mathrm{F} / \mathrm{B}$ ratio better than $30 \mathrm{~dB}$ and sidelobe levels better than $25 \mathrm{~dB}$ were achieved. Placing a large reflector behind BSA can improve F/B; however, it can introduce other intricacies such as increased wind resistance, large antenna size, and antenna loading. An electromagnetic scattering structure applied on the Radome is used in [59] to reduce back lobe radiation.

Beam Squint is another critical performance parameter for antenna radiation patterns. The beam squint refers to the deviation of the main beam direction from its boresight in the azimuth plane. The beam squint is measured in \pm degrees from the boresight direction. The squint can be measured as a $3 \mathrm{~dB}$ beam squint or a $10 \mathrm{~dB}$ beam squint, and the aim is to keep the squint as low as possible throughout the entire operating band for all elevation tilts. Generally, the squint gets worse with higher elevation tilts. In [26], beam squint up to $12^{\circ}$ is reported at $10^{\circ}$ elevation tilt. Different techniques are followed to minimize the beam squint. In [27], a combination of microstrip and a stripline PCB's are introduced in the radiation element to minimize the beam squint below $5^{\circ}$ for downtilt measured at $7^{\circ}$ and $0^{\circ}$. Another technique is to enforce symmetric current distribution on radiating elements to minimize squint. This is achieved in [38] by using the Pawsey stub balun to feed radiating elements and to reduce leaky current distortions to have HPBW within $54-76^{\circ}$. In [28], the beam squint $<4^{\circ}$ with a maximum $10^{\circ}$ down tilt is achieved through octagon-shape-folded dipoles as shown in Figure 12a.

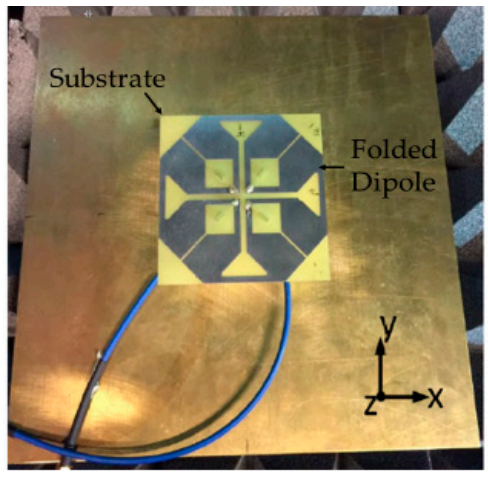

(a)

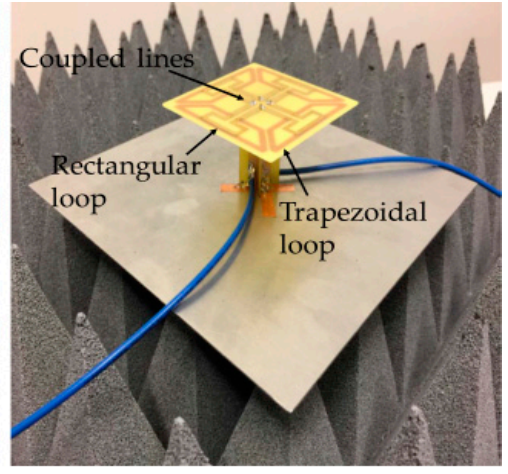

(b)

Figure 12. (a) Fabricated prototype of folded dipole [28]. (b) Fabricated Prototype of magnetoelectric loop dipole [29].

Cross-polar discrimination (XPD) is another important parameter when looking at radiation pattern performance. In general, the XPD above $10 \mathrm{~dB}$ in the sector is recommended for base station application. The magnetoelectric layered loop dipole configuration shown in Figure 12b, is used in [29] to achieve XPD over $20 \mathrm{~dB}$ in the boresight direction. Antenna gain is also a vital characteristic in BSA design. Operators prefer a positive gain slope across the band as the higher gain at higher frequencies compensates for the additional 
free space losses. In the azimuth, the gain in sector edge directions is lower compared to boresight due to gain roll-off. A lower gain roll-off in azimuth patterns is achieved in [30] by introducing a notch metal wall to radiating element, which enhances the gain by $2 \mathrm{~dB}$ at sector edge $\pm 60^{\circ}$ angle.

The aforementioned radiation pattern-related parameters are applicable for singleband and multiband antennas. However, in multiband antennas, radiation patterns can be severely impacted due to cross-band scattering when interleaved or embedded arrays. In a dual-band interspaced array, the high-frequency element patterns are impacted due to scattering from the currents induced in low-frequency elements and vice versa. The impact can be on multiple parameters such as beamwidth, squint, and XPD. Overcoming such impacts can be very difficult. It is often attempted to ensure that each radiating element is transparent to the other in their operating frequency bands, which is a challenging task. In [60], the high-frequency band (HB) pattern distortions caused by the lower frequency band (LB) radiating elements are minimized by introducing chokes into the LB element. These chokes are quarter-wavelength open circuit segments at high band frequencies, and this minimizes scattering. In [61], the printed dipole is segmented into smaller segments that are not resonant in the higher frequency band region, and each segment is connected to the other by inductive thin lines. This makes the lower band element transparent to the higher band radiating element. In [62], a cloaked antenna system is realized to minimize the scattering of closely located antennas. A dual-polarized mantle cover to cloak the dipole antenna is used in this work, and radiation performance is almost unaffected.

The aforementioned challenges for patterns are fundamental and equally applicable for single beam, multibeam, or steerable beams in BSAs. When it comes to $5 \mathrm{G}$, there are some additional challenges and complexities associated with the mMIMO and beamforming. As mentioned earlier in Section 2, there are two main beamforming technologies, namely analog and digital, used in BSAs for sub- $6 \mathrm{GHz}$. Although the analog beamforming is not true mMIMO, it is still used in some of the $5 \mathrm{G}$ base station antennas to form multiple beams. The true mMIMO in sub- $6 \mathrm{GHz}$ is achieved through digital beamforming in 5G BSAs.

The most popular techniques used for analog beamforming are based on either Butlermatrix circuits [63] or Luneburg lenses [64]. Compared to lenses, the Butler-matrix circuit implementations are compact, low-cost, and planar. The designers can incorporate the Butler matrix implementations with the feed distribution network. Therefore, it does not necessarily increase the antenna height. However, there are several challenges associated with the Butler matrix implementation such as dual-band operation, isolation between beams, side-lobe suppression, and wide operating bandwidth [65]. The branch line couplers used in the Butler matrix have inherent bandwidth limitations, and as a result, they cannot be designed to have multi-band operation. The approach is to have distinct Butler matrices for each band [66] to overcome this limitation. However, this comes with inherent crossband coupling challenges, which were discussed in Section 3.2. The narrowband challenges were addressed with wideband quadrature couplers and fixed-phase shifters in a Butler matrix [67]. Although there has been some reported literature on high-beam-to-beam isolation [68], it is still an ongoing challenge. One solution to minimize the sidelobes as well as grating lobes is achieved by changing the antenna element arrangement in [63].

In contrast to butler matrices, a careful design of a lens-based beamformer can provide stable radiation patterns, with low sidelobe levels in a wide band [8]. However, the size of the lens in front of the antenna increases the antenna height as well as weight. Therefore, low profile, low cost, and lightweight lenses remain a potential research topic for analog beamforming in BSAs. The other analog beamforming techniques reported in the literature include the use of metasurfaces [69], parabolic cylindrical reflectors [70], and reconfigurable parasitic radiators [71].

The digital beamforming architecture, which provides true mMIMO capability, has certain challenges as well. One of the key challenges is the design complexity. An example $4 \times 4 \mathrm{Tx} / \mathrm{Rx}$ dual polar mMIMO configuration for a BSA is shown in Figure 13. Each 
radiating element requires an RFIC to provide amplification and filtering, which are then connected to the digital beamformer. This dual polar Tx/Rx array requires in total $32 \mathrm{RFICs}$ and 8 baseband beamformers. All these components need to be placed closer to radiating element, making the integration of the antenna element and RF circuitry very complex. Unlike mm-wave designs, the sub-6 GHz designs cannot be realized as an integrated AiP in MMIC technology due to the large size of the antenna element. In addition, the large number of RFICs and digital processing results in high power consumption. Even with the state-of-the-art efficient power amplifiers available in the sub- $6 \mathrm{GHz}$ bands, the thermal dissipation from processors and RFICs remains a significant challenge that needs to be addressed in the design. Thermal vias and thermal pads are necessary at the back of the RF and digital electronics to dissipate the heat in these antennas [31]. The increased power consumption results in less value for money for the operators despite the capacity improvement. Some antenna designs have addressed this by limiting the real-time beamforming on the horizontal axis only [64]. The elevation beam tilting in this case is not done electronically and initially set by the remote electrical tilting mechanism using the legacy phase shifters. Then, the Azimuth beamforming is done using the phase and amplitude control among array columns.

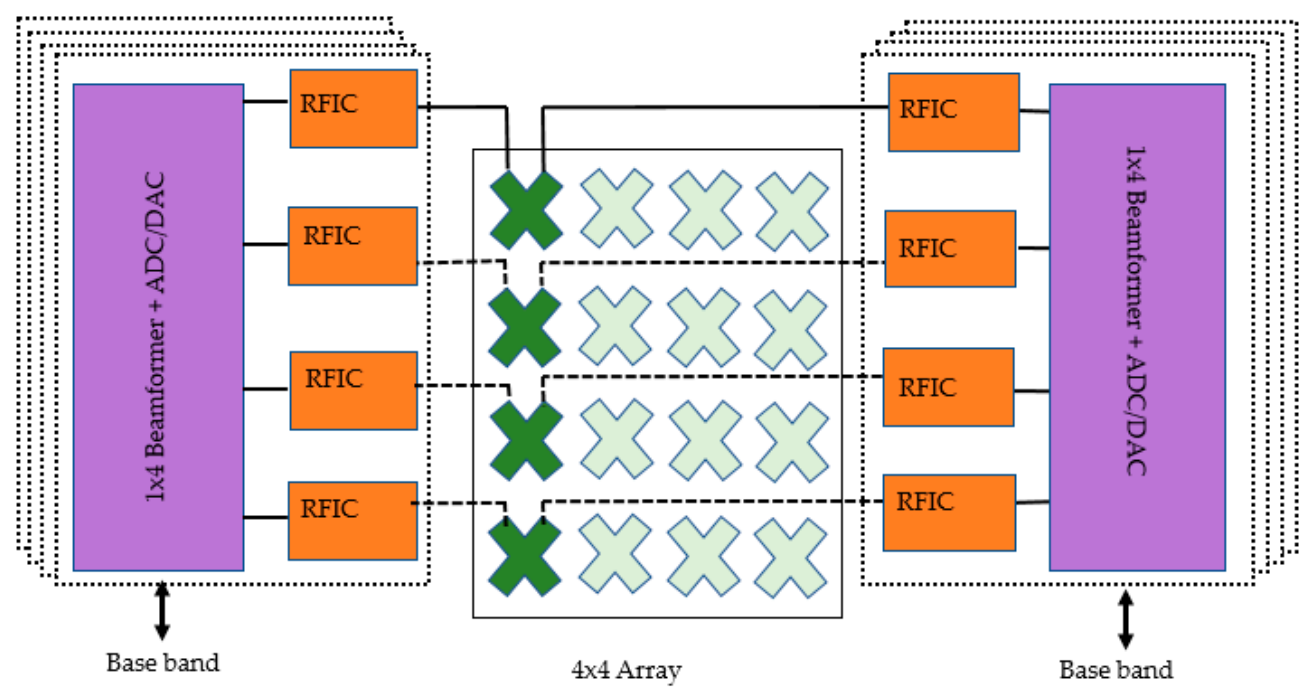

Figure 13. Components of a $4 \times 4 \mathrm{Tx} / \mathrm{Rx}$ dual polar mMIMO configuration.

Another challenge with the mMIMO antenna design is the calibration. The phase needs to be calibrated with high accuracy along the entire RF transceiver chain in order to ensure the expected beamforming gains. The amplifiers can have varying phases based on their operating conditions such as bias points, temperature, and frequency of operation, and these variations can lead to deviations from the expected phase distribution at the elements. As a result, the patterns may not form nulls, where it is expected that leads to increased interference with adjacent users. The antenna testing is another challenge for mMIMO as the access to RF inputs of the antenna is difficult with the other components in the RF transceiver chain. Therefore, instead of doing antenna pattern testing with an RF input, Over-the-Air (OTA) testing is required with the baseband IQ data as the input/output.

\subsection{Size and Cost}

Operators are keen to maximize the performance per unit area in the tower space. Therefore, they require compact antennas with better overall performance at a low cost. This requires the designs to be compact and low in cost. The miniaturizations are often achieved by having interspersed multiband arrays [4]. A comparison of different arrangement schemes for high-frequency elements and low-frequency elements is performed [2]. As shown in Figure 14, side-by-side schemes, up-and-down coaxial schemes, and embed- 
ded schemes were considered. Although the up-and-down scheme is simpler, cable losses increase due to the increased length of the main feed line. The embedded scheme has the advantage of compactness as two antennas are located within a single band antenna volume. However, embedded schemes exhibit challenges of isolation and pattern distortions. A single radiating element for both the low and high bands is used in[72,73] to reduce the number of required radiating elements and footprint. However, the required vertical element spacing for optimum elevation patterns is hard to achieve in this approach. Hence, the grating lobe levels are high. The dual broadband planer BSA configuration is followed in [32], where high band elements are nested inside lower band elements to achieve compactness.

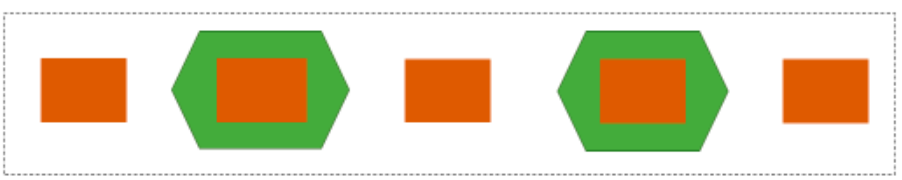

(a)

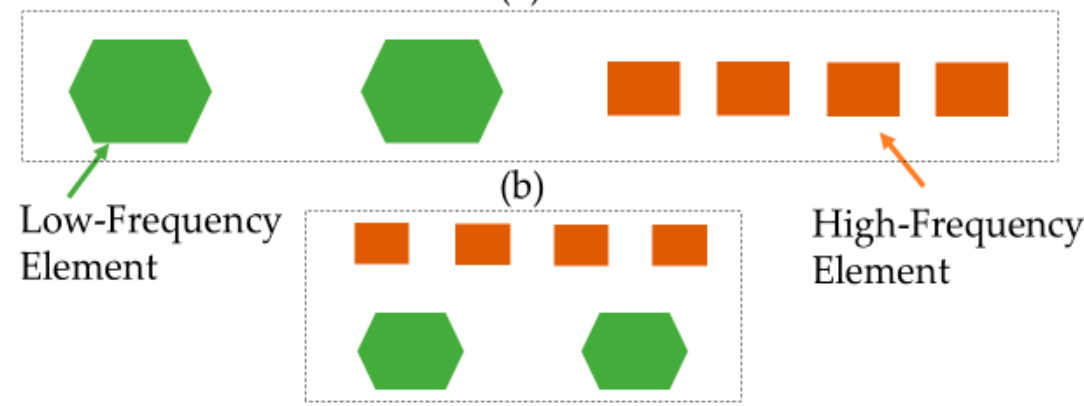

(c)

Figure 14. (a) Multiband embedded scheme; (b) multi band side-by-side scheme; (c) multiband -up-and-down coaxial scheme [2].

The lower cost in the antenna production is achieved by using low-cost, simple, printed antennas. The printed circuit board technologies reduces antenna assembly times. Another low-cost choice for enabling 5G BSA is 3D printing, which facilitates complex designs. Three-dimensional printing is an effective manufacturing method for designing MIMO antenna prototypes to reduce the cost. In [33], \pm 45 dual-polarized antenna is fabricated using 3D printing technology while achieving a wide bandwidth. Although printed antennas have a low-cost advantage, they can exhibit higher dielectric losses compared to die-cast radiating elements. Die-casting can be cost-effective if the entire element is made out from a cast reducing the assembly time. In addition to the cost incurred on radiating elements, the other RF components, such as phase shifters, may incur higher costs. A wiper phase shifter [74] can be a cost-effective solution as it is very compact but may have other disadvantages, such as limited control for null-filling in down tilts and the use of a large number of cables. Other types of phase shifters such as $[75,76]$ can overcome some of these limitations while reducing fabrication costs.

\section{Future Trends in 5G Base Station Antennas}

The foundation of any BSA antenna is the radiating elements in the arrays. Therefore, it is important to select wideband radiating elements with stable radiation patterns. Table 4 contains some of the recent state-of-the-art radiating elements that show wideband performance. Some of the design concepts used in the design of these elements can be used as the basis to develop more improved radiating elements for current and future 5G antennas. 
Table 4. Comparison of a selected set of wideband radiating elements used in BSAs.

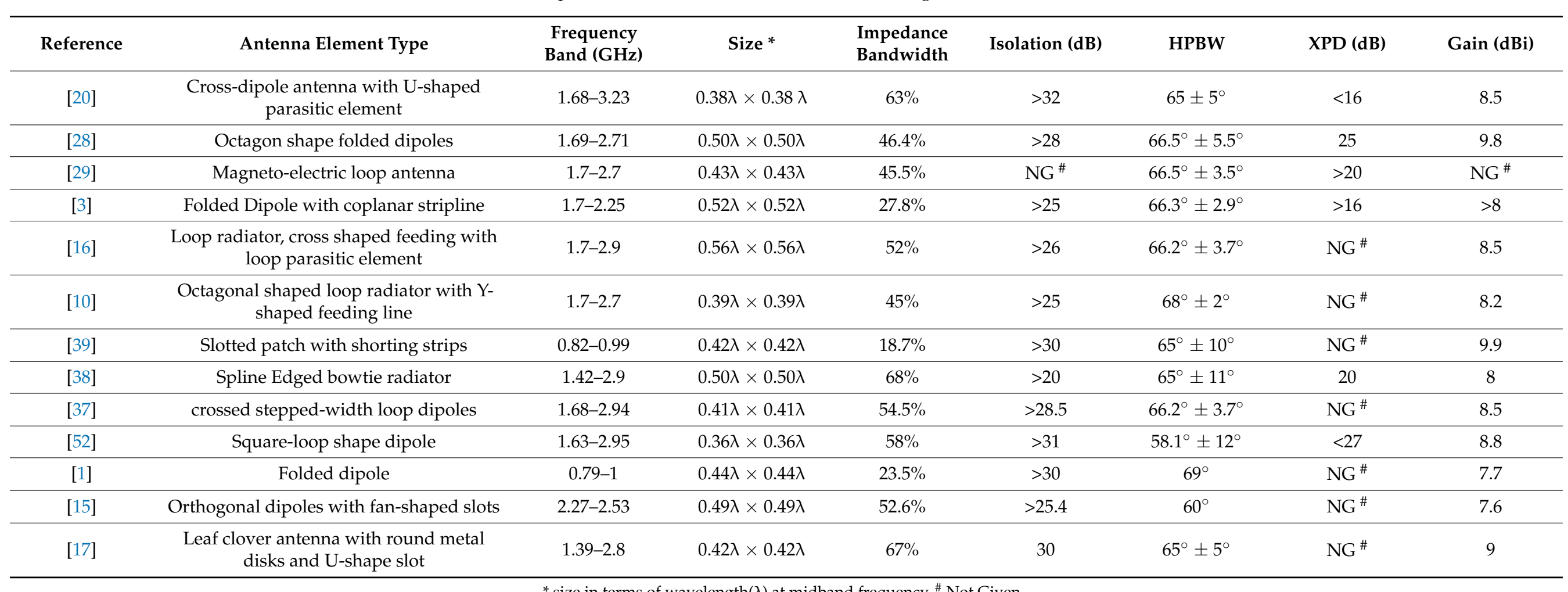

* size in terms of wavelength $(\lambda)$ at midband frequency, ${ }^{*}$ Not Given. 
The massive MIMO is one of the most popular topics among the 5G BSA community. Currently, the massive MIMO used in the 5G network is typically standalone, i.e., contains only one frequency band commonly referred to as mid-band $(2.6 \mathrm{GHz}-4.2 \mathrm{GHz})$ with 32 or 64 ports (eight dual-polarized columns with two or four rows). No other bands are integrated into those active antennas. The massive MIMO antennas require the radios to be used for each of the ports. Despite the high throughput advantage of these massive MIMO antennas, the extreme power consumption puts a significant loading on the electrical network. The operators cannot remove the existing $4 \mathrm{G}$ BSAs to reduce the power consumption since the current 5G massive MIMO antennas cannot still serve all the frequency bands. Therefore, the industry is leaning towards integrating legacy multiband 4G antennas with $5 \mathrm{G}$ massive MIMO antennas. One potential approach is to reduce the number of ports in massive MIMO BSAs from 32 to 16 and provide some space to integrate a legacy antenna. The aim is to strike a balance with operational cost and performance. The combination of legacy 4G and 5G massive MIMO still poses the challenges highlighted in the paper. For example, the low band (under $1 \mathrm{GHz}$ ) needs to be decoupled in an even wider band from 1.4 GHzto $4.2 \mathrm{GHz}$, which is very difficult. Moreover, the antenna profile is required to be slimmer for less wind loading, making the technical design even harder. Possibilities remain open to design novel wideband frequency selective surfaces to overcome some of these challenges to reduce coupling and improve patterns since more bands are now required to be integrated under one radome.

\section{Conclusions}

Base Station Antennas have evolved from simpler Omni antennas to multiband multibeam sectorized antennas over the last three decades. The antenna complexity has increased with each wireless generation, leading to more design challenges to antenna engineers. From LTE-A leading to 5G, sub-6 GHz BSA designs have multiple antenna arrays. This is due to several reasons, including the need to support MIMO capability and the need to maximize value for money by covering multiple bands. To achieve size savings, the multiple bands are interspersed in the design. The presence of multiple radiators introduces scattering, degrading the pattern performance of each band. Coupling between the close proximity elements leads to challenges in meeting impedance and isolation specifications. As a result, multiple techniques are applied by antenna designers such as cloaked dipoles, parasitic elements, FSSs, and filters to mitigate these challenges.

Author Contributions: All authors conceived and proposed the idea; all authors contributed to the structure of the paper. Wrote the paper under the supervision of D.N.T. All authors have read and agreed to the published version of the manuscript.

Funding: This research received no external funding.

Data Availability Statement: The data presented in this article can be obtained from the relevant references provided in this article.

Conflicts of Interest: The authors declare no conflict of interest.

\section{References}

1. Huang, H.; Liu, Y.; Gong, S. A Novel Dual-Broadband and Dual-Polarized Antenna for 2G/3G/LTE Base Stations. IEEE Trans. Antennas Propag. 2016, 64, 4113-4118. [CrossRef]

2. He, Y.; Pan, Z.; Cheng, X.; He, Y.; Qiao, J.; Tentzeris, M.M. A Novel Dual-Band, Dual-Polarized, Miniaturized and Low-Profile Base Station Antenna. IEEE Trans. Antennas Propag. 2015, 63, 5399-5408. [CrossRef]

3. Wen, D.; Zheng, D.; Chu, Q. A Dual-polarized Planar Antenna Using Four Folded Dipoles and Its Array for Base Stations. IEEE Trans. Antennas Propag. 2016, 64, 5536-5542. [CrossRef]

4. Liu, Y.; Wang, S.; Li, N.; Wang, J.; Zhao, J. A Compact Dual-Band Dual-Polarized Antenna With Filtering Structures for Sub-6 GHz Base Station Applications. IEEE Antennas Wirel. Propag. Lett. 2018, 17, 1764-1768. [CrossRef]

5. Mandhyan, A. 4G and 5G Capacity Solutions Comparative Study; Commscope: Hickory, NC, USA, 2019.

6. Kelly, I.; Zimmerman, M.; Butler, R.; Zheng, Y. Base Station Antenna Selection for LTE Networks; Commscope: Hickory, NC, USA, 2017. 
7. Zhu, H.; Sun, H.; Ding, C.; Guo, Y.J. Butler Matrix Based Multi-Beam Base Station Antenna Array. In Proceedings of the 2019 13th European Conference on Antennas and Propagation (EuCAP), Krakow, Poland, 31 March-5 April 2019; pp. 1-4.

8. Ansari, M.; Jones, B.; Zhu, H.; Shariati, N.; Guo, Y.J. A Highly Efficient Spherical Luneburg Lens for Low Microwave Frequencies Realized With a Metal-Based Artificial Medium. IEEE Trans. Antennas Propag. 2021, 69, 3758-3770. [CrossRef]

9. Mak, K.M.; Lai, H.W.; Luk, K.M. A 5G Wideband Patch Antenna With Antisymmetric L-shaped Probe Feeds. IEEE Trans. Antennas Propag. 2018, 66, 957-961. [CrossRef]

10. Chu, Q.; Wen, D.; Luo, Y. A Broadband \pm 45 Dual-Polarized Antenna With Y-Shaped Feeding Lines. IEEE Trans. Antennas Propag. 2015, 63, 483-490. [CrossRef]

11. Wang, W.; Liu, X.; Wu, Y.; Liu, Y. A Broadband Filtering Patch Antenna Using T-Probe, Transverse Stubs, and U-Slots. IEEE Access 2019, 7, 7502-7509. [CrossRef]

12. Wu, W.; Fan, R.; Zhang, Z.; Zhang, W.; Zhang, Q. A shorted dual-polarized cross bowtie dipole antenna for mobile communication Systems. In Proceedings of the 2014 XXXIth URSI General Assembly and Scientific Symposium (URSI GASS), Beijing, China, 16-23 August 2014; pp. 1-4.

13. Chu, Q.; Luo, Y. A Broadband Unidirectional Multi-Dipole Antenna with Very Stable Beamwidth. IEEE Trans. Antennas Propag. 2013, 61, 2847-2852. [CrossRef]

14. Zheng, D.; Chu, Q. A Multimode Wideband $\pm 45^{\circ}$ Dual-Polarized Antenna with Embedded Loops. IEEE Antennas Wirel. Propag. Lett. 2017, 16, 633-636. [CrossRef]

15. Huang, H.; Liu, Y.; Gong, S. A Broadband Dual-Polarized Base Station Antenna with Anti-Interference Capability. IEEE Antennas Wirel. Propag. Lett. 2017, 16, 613-616. [CrossRef]

16. Wen, D.; Zheng, D.; Chu, Q. A Wideband Differentially Fed Dual-Polarized Antenna with Stable Radiation Pattern for Base Stations. IEEE Trans. Antennas Propag. 2017, 65, 2248-2255. [CrossRef]

17. Cui, Y.; Wu, L.; Li, R. Bandwidth Enhancement of a Broadband Dual-Polarized Antenna for 2G/3G/4G and IMT Base Stations. IEEE Trans. Antennas Propag. 2018, 66, 7368-7373. [CrossRef]

18. Kraus, J.D.; Marhefkas, R.J. Antennas: For All Applications, 3rd ed.; Tempe, A.Z., Ed.; McGrw-Hill: New York, NY, USA, 2002; pp. 165-196.

19. Ye, L.H.; Zhang, X.Y.; Gao, Y.; Xue, Q. Wideband Dual-Polarized Four-Folded-Dipole Antenna Array With Stable Radiation Pattern for Base-Station Applications. IEEE Trans. Antennas Propag. 2020, 68, 4428-4436. [CrossRef]

20. Ding, C.F.; Zhang, X.Y.; Yu, M. Simple Dual-Polarized Filtering Antenna With Enhanced Bandwidth for Base Station Applications. IEEE Trans. Antennas Propag. 2020, 68, 4354-4361. [CrossRef]

21. Xue, Q.; Liao, S.W.; Xu, J.H. A Differentially-Driven Dual-Polarized Magneto-Electric Dipole Antenna. IEEE Trans. Antennas Propag. 2013, 61, 425-430. [CrossRef]

22. Liu, Y.; Wang, S.; Wang, X.; Jia, Y. A Differentially Fed Dual-Polarized Slot Antenna with High Isolation and Low Profile for Base Station Application. IEEE Antennas Wirel. Propag. Lett. 2019, 18, 303-307. [CrossRef]

23. Chiu, C.; Cheng, C.; Murch, R.D.; Rowell, C.R. Reduction of Mutual Coupling Between Closely-Packed Antenna Elements. IEEE Trans. Antennas Propag. 2007, 55, 1732-1738. [CrossRef]

24. Zhang, Y.; Zhang, X.Y.; Ye, L.; Pan, Y. Dual-Band Base Station Array Using Filtering Antenna Elements for Mutual Coupling Suppression. IEEE Trans. Antennas Propag. 2016, 64, 3423-3430. [CrossRef]

25. Fu, W.; Thalakotuna, D.; Liversidge, P. Stadium Antenna. WO Patent 2016054672 A1, 1 March 2016.

26. Timofeev, I.; Ai, X.; Teillet, A. Dual Polarized Three-Sector Base Station Antenna with Variable Beam Tilt. U.S. Patent 7196674 B2, 27 March 2007.

27. Bisiules, P.; Shooshtari, A.S. Full Wave Dipole Array Having Improved Squint Performance. WO Patent 2016137526 A1, 1 August 2017.

28. Sun, H.; Ding, C.; Jones, B.; Guo, Y.J. A Wideband Base Station Antenna Element with Stable Radiation Pattern and Reduced Beam Squint. IEEE Access 2017, 5, 23022-23031. [CrossRef]

29. Ding, C.; Sun, H.; Ziolkowski, R.W.; Guo, Y.J. A Dual Layered Loop Array Antenna for Base Stations with Enhanced CrossPolarization Discrimination. IEEE Trans. Antennas Propag. 2018, 66, 6975-6985. [CrossRef]

30. Yin, J.Y.; Zhang, L. Design of a Dual-Polarized Magneto-electric Dipole Antenna with Gain Improvement at Low Elevation Angle for a Base Station. IEEE Antennas Wirel. Propag. Lett. 2020, 19, 756-760. [CrossRef]

31. Walter, H. Sub-6 GHz mMIMO base stations meet 5G's size and weight challenges. Microw. J. 2019, 62, 40-52.

32. Cui, Y.; Li, R.; Wang, P. Novel Dual-Broadband Planar Antenna and Its Array for 2G/3G/LTE Base Stations. IEEE Trans. Antennas Propag. 2013, 61, 1132-1139. [CrossRef]

33. Li, Y.; Wang, C.; Yuan, H.; Liu, N.; Zhao, H.; Li, X. A 5G MIMO Antenna Manufactured by 3-D Printing Method. IEEE Antennas Wirel. Propag. Lett. 2017, 16, 657-660. [CrossRef]

34. Fournier, A.F.A. Recommendation on Base Station Antenna Standards (V11.1); NGMN Alliance: Frankfurt am Main, Germany, 2019.

35. Elsherbini, A.; Wu, J.; Sarabandi, K. Dual Polarized Wideband Directional Coupled Sectorial Loop Antennas for Radar and Mobile Base-Station Applications. IEEE Trans. Antennas Propag. 2015, 63, 1505-1513. [CrossRef]

36. Li, R.; Wu, T.; Pan, B.; Lim, K.; Laskar, J.; Tentzeris, M.M. Equivalent-Circuit Analysis of a Broadband Printed Dipole With Adjusted Integrated Balun and an Array for Base Station Applications. IEEE Trans. Antennas Propag. 2009, 57, $2180-2184$. 
37. Zheng, D.; Chu, Q. A Wideband Dual-Polarized Antenna with Two Independently Controllable Resonant Modes and Its Array for Base-Station Applications. IEEE Antennas Wirel. Propag. Lett. 2017, 16, 2014-2017. [CrossRef]

38. Zhang, Q.; Gao, Y. A Compact Broadband Dual-Polarized Antenna Array for Base Stations. IEEE Antennas Wirel. Propag. Lett. 2018, 17, 1073-1076. [CrossRef]

39. Nie, L.Y.; Lin, X.Q.; Chen, Y.J.; Zhang, J.; Wang, B.; Yang, Z.Q.; Fan, Y. A Low-Profile Coplanar Dual-Polarized and Dual-Band Base Station Antenna Array. IEEE Trans. Antennas Propag. 2018, 66, 6921-6929. [CrossRef]

40. $\mathrm{Wu}, \mathrm{R} . ; \mathrm{Chu}, \mathrm{Q}$. Resonator-Loaded Broadband Antenna for LTE700/GSM850/GSM900 Base Stations. IEEE Antennas Wirel. Propag. Lett. 2017, 16, 501-504. [CrossRef]

41. Zhao, L.; Wu, K. A Dual-Band Coupled Resonator Decoupling Network for Two Coupled Antennas. IEEE Trans. Antennas Propag. 2015, 63, 2843-2850. [CrossRef]

42. Tang, X.; Mouthaan, K.; Coetzee, J.C. Dual-band decoupling and matching network design for very closely spaced antennas. In Proceedings of the 2012 42nd European Microwave Conference, Amsterdam, The Netherlands, 29 October-1 November 2012; pp. 49-52.

43. Huang, H.; Liu, Y.; Gong, S. A Dual-Broadband, Dual-Polarized Base Station Antenna for 2G/3G/4G Applications. IEEE Antennas Wirel. Propag. Lett. 2017, 16, 1111-1114. [CrossRef]

44. Li, M.; Chen, X.; Zhang, A.; Kishk, A.A. Dual-Polarized Broadband Base Station Antenna Backed With Dielectric Cavity for 5G Communications. IEEE Antennas Wirel. Propag. Lett. 2019, 18, 2051-2055. [CrossRef]

45. Mavridou, M.; Feresidis, A.P.; Gardner, P. Tunable Double-Layer EBG Structures and Application to Antenna Isolation. IEEE Trans. Antennas Propag. 2016, 64, 70-79. [CrossRef]

46. Pan, Y.M.; Hu, P.F.; Zhang, X.Y.; Zheng, S.Y. A Low-Profile High-Gain and Wideband Filtering Antenna with Metasurface. IEEE Trans. Antennas Propag. 2016, 64, 2010-2016. [CrossRef]

47. Jin, J.Y.; Liao, S.; Xue, Q. Design of Filtering-Radiating Patch Antennas With Tunable Radiation Nulls for High Selectivity. IEEE Trans. Antennas Propag. 2018, 66, 2125-2130. [CrossRef]

48. Wu, T.L.; Pan, Y.M.; Hu, P.F.; Zheng, S.Y. Design of a Low Profile and Compact Omnidirectional Filtering Patch Antenna. IEEE Access 2017, 5, 1083-1089. [CrossRef]

49. Sun, G.; Wong, S.; Zhu, L.; Chu, Q. A Compact Printed Filtering Antenna With Good Suppression of Upper Harmonic Band. IEEE Antennas Wirel. Propag. Lett. 2016, 15, 1349-1352. [CrossRef]

50. Yang, W.; Chen, S.; Xue, Q.; Che, W.; Shen, G.; Feng, W. Novel Filtering Method Based on Metasurface Antenna and Its Application for Wideband High-Gain Filtering Antenna With Low Profile. IEEE Trans. Antennas Propag. 2019, 67, 1535-1544. [CrossRef]

51. Yang, S.J.; Cao, Y.F.; Pan, Y.M.; Wu, Y.; Hu, H.; Zhang, X.Y. Balun-Fed Dual-Polarized Broadband Filtering Antenna without Extra Filtering Structure. IEEE Antennas Wirel. Propag. Lett. 2020, 19, 656-660. [CrossRef]

52. Bao, Z.; Nie, Z.; Zong, X. A Novel Broadband Dual-Polarization Antenna Utilizing Strong Mutual Coupling. IEEE Trans. Antennas Propag. 2014, 62, 450-454. [CrossRef]

53. Chen, Y.; Zhao, J.; Yang, S. A Novel Stacked Antenna Configuration and its Applications in Dual-Band Shared-Aperture Base Station Antenna Array Designs. IEEE Trans. Antennas Propag. 2019, 67, 7234-7241. [CrossRef]

54. Zhu, Y.; Chen, Y.; Yang, S. Decoupling and Low-Profile Design of Dual-Band Dual-Polarized Base Station Antennas Using Frequency-Selective Surface. IEEE Trans. Antennas Propag. 2019, 67, 5272-5281. [CrossRef]

55. Afanasyev, P.; Matitsine, S.; Sledkov, V.; Lagoiski, P.; Matytsine, L.; DeMarco, T.; Tse-Tong, C. Multi-beam Luneburg lens antenna for cellular communications. In Proceedings of the 2015 9th European Conference on Antennas and Propagation (EuCAP), Lisbon, Portugal, 13-17 April 2015; pp. 1-4.

56. Matytsine, L.; Lagoiski, P.; Matytsine, M.; Matitsine, S. Large size, lightweight, Luneburg Lenses for multi-beam antenna applications. In Proceedings of the 2012 6th European Conference on Antennas and Propagation (EUCAP), Prague, Czech Republic, 26-30 March 2012; pp. 2266-2270.

57. Su, D.; Fu, D.; Wang, T.N.C.; Yang, H. Broadband Polarization Diversity Base Station Antenna for 3G Communication System. In Proceedings of the 2007 International Symposium on Microwave, Antenna, Propagation and EMC Technologies for Wireless Communications, Honolulu, HI, USA, 16-17 August 2007; pp. 593-596.

58. Su, D.; Qian, J.J.; Hua, Y.; Fu, D. A novel broadband polarization diversity antenna using a cross-pair of folded dipoles. IEEE Antennas Wirel. Propag. Lett. 2005, 4, 433-435.

59. Wu, C.; Yang, C.F. Method and Apparatus for Improving Antenna Radiation Patterns. U.S. Patent 7081865 B2, 25 July 2006.

60. Sun, H.H.; Ding, C.; Zhu, H.; Jones, B.; Guo, Y.J. Suppression of Cross-Band Scattering in Multiband Antenna Arrays. IEEE Trans. Antennas Propag. 2019, 67, 2379-2389. [CrossRef]

61. Isik, O.; Gripo, P.; Thalakotuna, D.; Liversidge, P. Cloaked Low Band Elements for Multiband Radiating Arrays. U.S. Patent 10 439285 B2, 8 October 2019.

62. Soric, J.C.; Monti, A.; Toscano, A.; Bilotti, F.; Alù, A. Dual-Polarized Reduction of Dipole Antenna Blockage Using Mantle Cloaks. IEEE Trans. Antennas Propag. 2015, 63, 4827-4834. [CrossRef]

63. Li, T.; Li, Q.; Zhang, M.; Zhang, A.X.; Zhang, J.; Chen, X. Four-beam Antenna Array with Low Side-lobe for Base Station. In Proceedings of the Application, 2019 Photonics \& Electromagnetics Research Symposium-Fall (PIERS-Fall), Xiamen, China, 17-20 December 2019; pp. 2796-2805.

64. Hamdy, D.M.N. An Introduction to LTE Smart Base Station Antennas; Commscope: Hickory, NC, USA, 2017. 
65. Wu, Z.; Wu, B.; Su, Z.; Zhang, X. Development challenges for 5G base station antennas. In Proceedings of the 2018 International Workshop on Antenna Technology (iWAT), Nanjing, China, 5-7 March 2018; pp. 1-3.

66. Zhang, X.; Xue, D.; Ye, L.; Pan, Y.; Zhang, Y. Compact Dual-Band Dual-Polarized Interleaved Two-Beam Array With Stable Radiation Pattern Based on Filtering Elements. IEEE Trans. Antennas Propag. 2017, 65, 4566-4575. [CrossRef]

67. Zhu, H.; Sun, H.; Jones, B.; Ding, C.; Guo, Y.J. Wideband Dual-Polarized Multiple Beam-Forming Antenna Arrays. IEEE Trans. Antennas Propag. 2019, 67, 1590-1604. [CrossRef]

68. Shen, L.; Wang, H.; Lotz, W.; Jamali, H. Dual Polarization 4x4 MIMO Sub-6GHz Multi-Beam Base Station Antennas. In Proceedings of the 2019 International Symposium on Antennas and Propagation (ISAP), Xi'an, China, 27-30 October 2019; pp. 1-3.

69. Gu, L.; Yang, W.; Che, W.; Chen, D.; Zhang, Y.; Feng, W. A Dual-Steerable-Beam Multi-Slot Coupled Metasurface Antenna. In Proceedings of the 2018 IEEE International Conference on Computational Electromagnetics (ICCEM), Chengdu, China, 26-28 March 2018; pp. 1-3.

70. Sanad, M.; Hassan, N. A Sub-6 GHz Multi-Beam Base Station Antenna for 5G with an Arbitrary Beam-Tilting for Each Beam. In Proceedings of the 2019 IEEE Radio and Wireless Symposium (RWS), Orlando, FL, USA, 20-23 January 2019; pp. 1-4.

71. Kayani, H.A.; Gueuning, Q.; Goreux, N.; Vanhoenacker-Janvier, D.; Oestges, C.; Craeye, C. Reconfigurable Cellular Base Station Antenna Consisting of Parasitic Radiators. IEEE Trans. Ind. Electron. 2020, 67, 7083-7093. [CrossRef]

72. Tefiku, F.; Grimes, C.A. Design of broad-band and dual-band antennas comprised of series-fed printed-strip dipole pairs. IEEE Trans. Antennas Propag. 2000, 48, 895-900. [CrossRef]

73. Qi, X.; Fushun, Z.; Baohua, S.; Yanlin, Z.; Qizhong, L. A novel dual-band Yagi-Uda antenna for wireless communications. In Proceedings of the 9th International Symposium on Antennas, Propagation and EM Theory, Guangzhou, China, 29 November-2 December 2010; pp. 289-292.

74. Ding, G.; Zimmerman, M.; Yu, J.; Qin, H. Base Station Antennas including Wiper Phase Shifters. EP Patent 3588 670A1, 1 January 2020.

75. Xiao, W.; Xiao, Z.; Su, W. Base Station Antenna. U.S. Patent 2016/0248156 A1, 25 August 2016.

76. He, Y.; Li, J.; Wong, S.W.; Pan, X.; Zhang, L.; Chen, Z.N. A Miniaturized Base Station Antenna with Novel Phase Shifter for 3G/LTE Applications. IEEE Access 2018, 6, 52877-52888. [CrossRef] 